\title{
La influencia de Ronald Dworkin en la jurisprudencia del Tribunal Electoral del Poder Judicial de la Federación
}

\author{
Ronald Dworkin's influence in the Jurisprudence \\ of the Electoral Court of the Judicial Power \\ of the Federation
}

\section{Raúl Montoya Zamora*}

\section{Sumario:}

I. Introducción

II. El pensamiento de Ronald Dworkin

III. La influencia de Dworkin en la jurisprudencia del Tribunal

Electoral del Poder Judicial de la Federación

IV. Fuentes consultadas

* Doctor en Derecho por la Universidad Juárez del Estado de Durango; especialista en Justicia Constitucional y Procesos Constitucionales por la Universidad de Castilla-La Mancha, Toledo, España; perfil deseable PROMEP vigente; miembro del Sistema Nacional de Investigadores; investigador en el Instituto de Investigaciones Jurídicas de la Universidad Juárez del Estado de Durango. 
Esta revista forma parte del acervo de la Biblioteca Jurídica Virtual del Instituto de Investigaciones Jurídicas de la UNAM

\section{Resumen:}

El presente trabajo tiene como objetivo central presentar someramente algunas de las tesis principales de Ronald Dworkin, y la influencia de este autor en la práctica judicial del Tribunal Electoral del Poder Judicial de la Federación, con lo que habré también de demostrar el vínculo existente entre teoría y práctica judicial.

En concreto, centraré mi exposición en una de las tesis de Dworkin que a la fecha, sigue siendo el principal motivo de disputa entre los teóricos del derecho, a saber, la separación conceptual entre el derecho y la moral, y la idea de un sistema jurídico conformado sólo por reglas, que dan pauta a la operación lógica de subsunción.

Para lograr el objetivo trazado, en primer lugar se expondrá brevemente el pensamiento del heredero de Hart en la Universidad de Oxford, y posteriormente se analizarán algunos criterios del Tribunal Electoral del Poder Judicial de la Federación, en donde se destaca la influencia de nuestro autor, argumentando paralelamente, el vínculo sustancial entre teoría y práctica judicial.

\section{Abstract:}

This paper seeks to present some of the main thesis of Ronald Dworkin, and the influence of his work in the judicial practice at the Federal Electoral Court, thus, demonstrating the link between theory and judicial practice.

Specifically, I will focus my discussion on one of Dworkin's thesis that currently remains as the most controversial aspects among legal academics, namely, the conceptual separation between law and morality, and the idea of a system considering only legal rules that give tone to the logical operation of subsumtion.

To achieve this, we first briefly describe the thinking of the heir to Hart at the University of Oxford, and then discuss some precedents of the Federal Electoral Court, which highlights the influence of our author, arguing the substantial link between theory and judicial practice.

Palabras clave: Ronald Dworkin, jurisprudencia electoral, Tribunal Electoral, práctica judicial.

Descriptors: Ronald Dworkin, electoral jurisprudence, Federal Electoral Court, judicial practice. 


\section{Introducción}

Una de las ramas del derecho que me resulta más apasionante, y a la que he dedicado una buena parte de mi vida profesional, es el derecho electoral.

El derecho electoral mexicano, ha evolucionado a pasos agigantados no sólo por los constantes procesos de reformas constitucionales y legales, sino también, por la influencia de las decisiones judiciales a cargo del Tribunal Electoral del Poder Judicial de la Federación (TEPJF), sin desconocer, que los tribunales electorales de los estados también realizan grandes aportaciones en el desarrollo del derecho electoral en México.

La evolución jurisprudencial del derecho electoral, se debe en buena medida, a que los órganos jurisdiccionales utilizan diversos insumos, distintos a los estrictamente normativos, en la resolución de los casos controvertidos que son sometidos a su consideración.

En efecto, la interpretación de las premisas normativas y fácticas, no sólo la hacen tomando en cuenta las normas en abstracto y el material probatorio en bruto, sino que incorporan teorías (jurídicas, filosóficas, dogmáticas, de valoración de las pruebas, etcétera), que les permiten atribuir un significado concreto a las normas y a las pruebas, en la resolución de las controversias electorales. ${ }^{1}$

En ese sentido, vemos que el desarrollo jurisprudencial del derecho electoral, se encuentra estrechamente vinculado a la teoría o teorías que utilizan los operadores jurídicos en la solución de las controversias.

Uno de los tantos teóricos que ha influido en la evolución de la jurisprudencia del TEPJF, ${ }^{2}$ es el destacado ius filósofo estadounidense Ronald Dworkin.

Así las cosas, el presente trabajo tiene como objetivo central, presentar someramente algunas de las tesis principales de Ronald Dworkin, y la influencia de este autor en la práctica judicial del TEPJF, con

1 Cfr. Cáceres Nieto, Enrique, Constructivismo jurídico y metateoría del derecho, México, UNAM, 2007.

2 También podemos encontrar la influencia de otros autores como son Jerzy Wróbleski, Luigi Ferrajoli, Robert Alexy, entre otros, que han permitido una notable evolución del derecho electoral en México. 
lo que habré también de demostrar el vínculo existente entre teoría y práctica judicial.

En concreto, centraré mi exposición en una de las tesis de Dworkin que a la fecha, sigue siendo el principal motivo de disputa entre los teóricos del derecho, a saber, la separación conceptual entre el derecho y la moral, y la idea de un sistema jurídico conformado sólo por reglas, que dan pauta a la operación lógica de subsunción.

Dworkin, como se verá, no acepta la mencionada tesis, y por el contrario, se pronuncia por un vínculo indisoluble entre derecho y moral, y por tanto, de un sistema jurídico conformado no sólo por reglas, sino por principios.

Para lograr el objetivo trazado, en primer lugar se expondrá brevemente el pensamiento del heredero de Hart en la Universidad de Oxford, y posteriormente se analizarán algunos criterios del TEPJF, en donde se destaca la influencia de nuestro autor, argumentando paralelamente, el vínculo sustancial entre teoría y práctica judicial.

\section{El pensamiento de Ronald Dworkin}

Ronald Dworkin, parte de una acepción que se contrapone a las teorías del derecho positivas como las de Kelsen, Austin y Hart, que de manera notable, presuponen una separación entre derecho y moral, y un sistema jurídico conformado siempre por reglas.

Dworkin toma como punto de partida, su crítica al modelo positivista, por presentar éste una separación entre derecho y moral, e introduce, por oposición, su teoría sobre los principios, que le llevan a basarse en una concepción interpretativa del derecho. Le confiere al juez, una importancia decisiva en el desarrollo de la responsabilidad de las decisiones judiciales. ${ }^{3}$

Para Dworkin, el sistema jurídico además de reglas, está conformado por principios, y estos deben de permitir que exista una única respuesta correcta en el caso de que las reglas no lo permitan. Añade que la única respuesta correcta sería aquella que mejor pueda justificarse a través de una teoría sustantiva que contenga los principios y ponderaciones de principios que mejor correspondan con la Constitución,

3 Dworkin, Ronald, Los derechos en serio, Barcelona, Ariel, 1999, cap. 13. 
las reglas de derecho y los precedentes. Dicha tarea es encomendada al súper juez Hércules dotado de una habilidad, sabiduría, paciencia y agudeza sobrehumanas. ${ }^{4}$

Los principios, en sentido estricto, son definidos por Dworkin, como estándares que han de observarse en virtud de una exigencia de justicia, equidad, o de alguna otra dimensión de la moralidad. ${ }^{5}$

Los principios se distinguen de las reglas, en que éstas establecen sus condiciones de aplicación, en tanto que los principios, suministran las razones para decidir en un sentido determinado, pero carecen de contenido específico, no establecen las condiciones de aplicación. En ese sentido, las reglas son o no aplicables en una fórmula todo o nada. En caso de conflicto entre dos reglas, sólo una puede ser válida. ${ }^{6}$

En cambio, los principios tienen una dimensión de peso, que en caso de conflicto, la prevalencia de uno no significa que el otro o los otros principios pierdan validez, de tal manera que, en un supuesto distinto donde se presente el mismo conflicto, pueda ser aplicado preferentemente el principio que en el primer caso fue desplazado. Bajo esta concepción, mientras las reglas se subsumen, los principios se ponderan.

Otra diferencia fundamental entre reglas y principios, es que las reglas pueden ser identificadas mediante un test de origen, mientras que los principios no. De acuerdo con lo anterior, sabemos que una regla pertenece a un sistema jurídico determinado, si se puede deducir su validez de una norma anterior, así hasta llegar a la Constitución. Mientras que no se puede deducir la validez de un principio por su origen, sino por su fuerza argumentativa, es decir, por su peso específico, por su contenido, de acuerdo con un complicado procedimiento de búsqueda de la más sólida teoría del derecho. ${ }^{7}$

En esta parte, lo que Dworkin pretende demostrar es que los jueces recurren con frecuencia a estándares que no pueden ser identificados mediante la regla de reconocimiento hartiana, y en vinculación con ello, que existen deberes jurídicos que no hallan su fundamento en una práctica social. A partir de lo anterior, Dworkin considera que

${ }_{4}$ Dworkin, Ronald, cit. pos., Alexy, Robert, "Sistema jurídico, principios jurídicos y razón práctica”, Doxa, núm. 5, 1988, pp. 139 y 140.

5 Dworkin, Ronald, Los derechos en serio, cit., p. 72.

6 Ibidem, pp. 22 y ss.

7 Idem. 
los principios no pueden identificarse por referencia al origen en un cierto legislador o Tribunal, sino por el sentido de convivencia u oportunidad que se desarrollan en el tiempo. ${ }^{8}$

Nuestro autor, para identificar cuándo estamos ante la presencia de un principio, había escrito:

Fundamentar nuestra afirmación de que cierto principio es un principio de derecho, mencionaríamos cualquier caso anterior... Mencionaríamos también cualquier ley que pareciera ejemplificarlo... A menos que llegásemos a encontrar el apoyo de algún antecedente institucional, no podríamos demostrar nuestro caso. ${ }^{9}$

Lo anterior parecía dar cabida a una nueva regla de reconocimiento, no obstante, Dworkin se resistió a desarrollar su criterio de apoyo institucional. Así, Dworkin apunta: "Un principio es un principio del derecho si figura de la teoría del derecho más lógica y mejor fundada que se pueda presentar como justificación de las normas institucionales y sustantivas explícitas.... ${ }^{10}$ Lo que nos lleva a "justificar las normas establecidas, identificando las preocupaciones y tradiciones morales de la comunidad... (por ende) conduce al jurista a profundizar en la teoría política y moral". ${ }^{11}$

Con todo, reglas y principios, establecen obligaciones vinculantes para el juez; éste los descubre, no asume una función creativa. Para Dworkin, los principios que son inescindibles de la moral, entran en juego cuando el derecho explícito es insuficiente, no cuando es inmoral.

Según Dworkin, todo sistema jurídico, que se guíe en su interpretación por principios, ha de ir más allá del simple análisis del texto y estar dispuesto a argumentar a favor de preservar los derechos fundamentales. De ahí que las normas y los principios sean esenciales para intentar llegar a "soluciones correctas" racionalmente motivadas. De esa manera, Dworkin opina que ante casos dificultosos, los jueces han de asistir inexorablemente a los principios. Diseña la necesidad en primer lugar, el pretender formar los fallos judiciales desde el derecho válido, con las decisiones tomadas por los sistemas políticos en segun-

\footnotetext{
8 Ibidem, p. 95.

9 Idem.

10 Ibidem, p. 128.

11 Ibidem, p. 129.
} 
do lugar. Para ello, se basa en la teoría de los derechos individuales, los cuales tienen un sentido deontológico que permite una justificación sustentada en los principios, con el fin de pretender buscar decisiones correctas. Tales principios suministran argumentos para reconstruir normativamente y mediante justificaciones, el derecho vigente. Una teoría del derecho vista desde esta perspectiva, debe pretender encontrar principios y objetivos válidos desde los cuales, un orden jurídico concreto pueda quedar reconocido en sus elementos esenciales; de tal manera que todas las decisiones judiciales sean razonables y coherentes, y esto sólo lo puede hacer un juez que tiene a Hércules como modelo. $^{12}$

Dworkin en su obra El imperio de la justicia, retoma sus planteamientos sobre la única respuesta correcta. Así, expone su tesis de la siguiente manera: "Según el derecho como integridad, las propuestas de la ley son verdaderas si figuran o surgen como consecuencias de principios de justicia, equidad y debido proceso que proporcionan la mejor interpretación constructiva de la práctica legal de la comunidad". ${ }^{13}$

Dworkin afirma: "En los casos difíciles, los principios desempeñan un papel esencial en los argumentos que fundamentan juicios referentes a determinados derechos y obligaciones jurídicas". ${ }^{14}$ Dworkin confía más en la función de los jueces para hacer valer los derechos fundamentales.

Dworkin asume que si bien es cierto que un proceso constitucional concluye con la adopción de un catálogo de derechos fundamentales, éstos tienen que ser interpretados e implementados, lo que lo lleva a manifestar que a las normas es necesario interpretarlas antes que se les pueda aplicar a casos concretos por parte del juez, quien debe seguir las directrices del legislador. Para ello introduce la distinción entre argumentos de principio - protege derechos individuales - y argumentos políticos - que protegen derechos colectivos-. El legislador obra desde argumentos políticos y si los tribunales son delegados por parte del legislador, entonces deben tener competencia para basar sus decisiones desde argumentos de principio, esto es, que la justificación

\footnotetext{
12 Dworkin, Ronald, El imperio de la justicia, Barcelona, Gedisa, 1998, p. 164.

13 Idem.

${ }_{14}$ Dworkin, Ronald, Los derechos en serio, cit., p. 80.
} 
de una decisión política respeta o asegura el derecho del grupo o los individuos. ${ }^{15}$

Dworkin argumenta que ante una única resolución correcta, el juez ha de justificar por medio de razones, por qué ha optado por esa decisión, basado, claro está, fundamentalmente en proteger los derechos de los individuos y grupos antes que cualquier otra opción. Esto podría llevar a que, cuando los jueces deciden han de hacerlo pensado que sus juicios al ser interpretados por la comunidad jurídica y por los implicados en el caso, lo están haciendo de forma deliberativa pues, ante una "pésima" y poco justificada decisión, los afectados podrían demandar ante una instancia superior la revisión o revocación de la decisión. Para Dworkin el raciocinio jurídico es un adiestramiento que se edifica interpretativamente, de ahí que su teoría del derecho tenga como sustento la interpretación. El derecho tiene como función la interpretación de las prácticas sociales desde un plano "constructivista" basado en principios y valores - los principios ofrecen la mejor justificación posible de la justicia, que puede ser brindada por medio del derecho-; es una teoría normativa de la interpretación que como lo explica, debe entenderse desde la opción por "el mejor ejemplo posible" a seguir desde valores morales. La respuesta correcta surge de la adecuada búsqueda para solucionar ese determinado caso. ${ }^{16}$

Así, cuando dos teorías inferidas a partir del derecho vigente, concurren en la explicación de un sistema jurídico, deberá preferirse la que sea moralmente más fuerte; ya que una mejor moral, supone una mejor justificación del ordenamiento. ${ }^{17}$

Empero, ¿qué postura debe asumir Hércules cuando se dé un conflicto entre los materiales jurídicos vigentes y los derechos morales básicos? Dworkin responde: "Es posible que deba mentir, que deba ocultar el Derecho válido; bien es cierto que sería poco aconsejable convertir esta mentira en asunto de teoría de la jurisprudencia". ${ }^{18}$

En ese orden de ideas, Dworkin sostiene textualmente lo siguiente: "People often stand to gain or lose more by one judge's nod than they could by any general act of Congress or Parliament". ${ }^{19}$

15 Ibidem, p. 147.

16 Ibidem, pp. 403 y 404.

17 Ibidem, p. 456.

18 Ibidem, p. 451.

19 La traducción de lo anterior queda de la siguiente manera: "Las personas resisten a menudo ganar o perder más por la inclinación de un juez que por cualquier acto general 
Luego entonces, la actividad judicial a través de la interpretación y aplicación de los principios constitucionales, tiende a proteger y garantizar derechos concretos de los individuos y grupos, por lo que queda depositar toda nuestra confianza en ese grupo de jueces para que tomen las mejores decisiones; si no con la única respuesta correcta, sí la más correcta posible.

Esto nos lleva a otro de los argumentos centrales de la obra de Dworkin: el significado y alcance de la actividad de los jueces, en especial, de la discrecionalidad judicial.

La postura de Hart al respecto, parece ser el blanco de la crítica antipositivista de Dworkin. ${ }^{20}$ Para Hart, los jueces no se comportan como legisladores, sino que obtienen de las leyes, de los precedentes, las pautas fundamentales para tomar sus decisiones. No obstante, esas leyes y precedentes no son lo suficientemente claras, ni pueden contemplar todos los supuestos de que implican la complejidad de la vida social. Es entonces, cuando los jueces despliegan una actividad que puede calificarse como creativa.

Con ese respecto Hart afirma:

La textura abierta del Derecho significa que hay, por cierto, áreas de conducta donde mucho debe dejarse para que sea desarrollado por los tribunales o por los funcionarios que procuran hallar un compromiso, a la luz de las circunstancias, entre los intereses en conflicto, cuyo peso varía de caso a caso. ${ }^{21}$

Dworkin por el contrario, niega toda discrecionalidad fuerte de los jueces, que supondría la ausencia de normas y principios para resolver una controversia. Sin embargo, acepta una discrecionalidad "débil", dado que todos los jueces realizan una actividad de discernimiento, una argumentación racional, y porque algunos tribunales adoptan la decisión final e inapelable sobre los conflictos.

En ese sentido, Dworkin reconoce completamente la autosuficiencia del derecho. Al juez Hércules le corresponde la tarea de desarrollar la mejor y más coherente teoría que explique y justifique mejor el de-

de Congreso o Parlamento". Cfr. Dworkin, Ronald, Law's Empire, Londres, Fontana Press, 1986, p. 1.

20 Dworkin, Ronald, Los derechos en serio, cit., pp. 413 y ss.

${ }^{21}$ Hart, H. L. A., El concepto de derecho, 2a ed., trad. de Genaro Carrió, México, UNAM, 1980. 
Esta revista forma parte del acervo de la Biblioteca Jurídica Virtual del Instituto de Investigaciones Jurídicas de la UNAM

recho explicito. Por tanto, debe abstenerse de crear normas, ya que las partes en el conflicto esperan que se declare el derecho, con base en un derecho propio y preexistente.

Nuestro autor, desarrolla su teoría de la decisión judicial en el capítulo de los “casos difíciles". En él, señala que el positivismo hierra, porque los jueces, recurriendo a los principios, siempre disponen de material jurídico suficiente para resolver cualquier conflicto, por difícil que pareciera. Además, sostiene que el positivismo alienta una función jurisdiccional antidemocrática, porque los jueces no desempeñan un poder representativo y, en todo caso, la atribución de un papel creativo afecta la división de poderes. De igual modo, argumenta que es lesiva para los derechos, porque si sus decisiones se producen con posterioridad, desaparece el postulado fundamental de la previsibilidad de las acciones, y con ello, de la seguridad jurídica. ${ }^{22}$

El capítulo V de la obra de Los derechos en serio, denominado, "Los casos constitucionales", ${ }^{23}$ constituye una puntualizada refutación a la doctrina que postula el riguroso sometimiento del juez al texto constitucional, en defensa del activismo judicial.

De acuerdo con Dworkin, en el activismo judicial no hay usurpación de los poderes de la mayoría, ni revisión constitucional, ni contradicción con su idea de la judicatura como cuerpo no político y sometido rigurosamente al derecho. La Constitución, no es un texto pesado, ni se compone sólo de fórmulas bien precisas y delimitadas. En Estados Unidos, "La Constitución, y particularmente el Bill of Rights, está destinada a proteger a los ciudadanos... contra ciertas decisiones que podría querer tomar una mayoría". ${ }^{24}$

Acorde a lo anterior, una premisa fundamental en la teoría de Dworkin, es respecto del papel que le corresponde al juez que en verdad quiera asumir la defensa de la Constitución. Este juez, no debe perder de vista que ésta descansa en una muy concreta teoría moral, cuyo postulado capital es que los hombres tienen derechos morales oponibles al Estado. Derechos que no pueden ser objeto de negociación política, y cuya protección requiere profundizar en el sentido que

${ }^{22}$ Las objeciones de Dworkin al positivismo, han sido respondidas por Hart, H. L. A., "El nuevo desafío al positivismo jurídico", trad. de F. Laporta, L. Hierro y J. R. Páramo, Sistema, núm. 36, mayo de 1980, pp. 10 y 11.

${ }^{23}$ Fue publicado originalmente con el título "The Jurisprudence of Richard Nixon". Detalla la polémica entre Nixon y el juez Warren.

${ }_{24}$ Dworkin, Ronald, Los derechos en serio, cit., p. 211. 
se la atribuye a los textos normativos. El estado de cosas citado, requiere a decir de Dworkin: "Un Tribunal activista, en el sentido que debe estar preparado para formular y resolver cuestiones de moralidad política". ${ }^{25}$

Es por ello, que para nuestro autor, los jueces no son órganos políticos, porque de lo contrario, carecerían de legitimidad para oponerse de modo eficaz a los designios de la mayoría, ni podrían sostener que sus decisiones son más justas que las del gobierno.

Para garantizar el imperio de la Constitución, Dworkin refiere que los jueces deben estar dispuestos a desempeñar un papel activo en defensa de la teoría moral sobre la que reposa todo el sistema.

En la teoría de nuestro autor, se tiene en cuenta que la Constitución incorpora preceptos bien delimitados y completos, cuyo significado es siempre idéntico por aludir a una realidad determinada y conocida, y por tanto, que no requieren de ningún esfuerzo interpretativo. Dworkin denomina a lo anterior "concepciones", que el constituyente quiso hacer perdurar como decisiones básicas del sistema. A lo anterior, Dworkin opone los llamados "conceptos" constitucionales, entendidos como puntos de vista de los constituyentes, encerrados en términos vagos, como referencias a estándares de conducta cuya concreción depende de las concepciones del momento. Para dotar de significado a los conceptos, el juez no debe de satisfacer la concepción que tuvo el constituyente, sino en determinar la concepción que (en el momento) mejor se ajuste al estándar incorporado en la Constitución: ello de acuerdo a la tesis fundamental que adopta la fusión del derecho constitucional y la teoría ética. ${ }^{26}$

De tal suerte, Dworkin establece: "Si quienes promulgaron las cláusulas amplias hubieran tenido la intención de formular concepciones particulares, habrían encontrado el tipo de lenguaje que convencionalmente se usa para hacerlo". ${ }^{27}$ En consecuencia, el juez se apegará a la Constitución, si toma su propia decisión acerca de determinado concepto en particular, en vez de seguir la concepción que el legislador tuvo en cuenta.

Otro aspecto fundamental en el pensamiento de Dworkin, es su postura en torno a los derechos humanos. Así, frente a una teoría polí-

25 Ibidem, p. 231.

26 Ibidem, p. 233.

27 Ibidem, p. 215. 
tica basada en los objetivos - utilitarismo- o en los deberes, nuestro autor nos propone una teoría política basada en los derechos; ${ }^{28}$ una teoría basada en la noción de derechos naturales anteriores a toda ley, convención o contrato hipotético, y que por ello no están sujetos a negociaciones ni al cálculo de intereses sociales. ${ }^{29}$

Precisamente en eso consiste tomarse los derechos en serio. Según Dworkin, un gobierno para quien los derechos no sean un simple recurso retórico, un gobierno que reconozca los derechos: "Debe prescindir de la aseveración de que los ciudadanos jamás tienen derecho a infringir sus leyes, y no debe definir los derechos de los ciudadanos de tal modo que queden aislados por supuestas razones del bien general". ${ }^{30}$

De lo anterior se advierte por qué Dworkin señala la desobediencia de la ley, como rasgo distintivo de un derecho fundamental que lo sea auténticamente.

Los derechos individuales se convierten así, en el fundamento de todo sistema jurídico-político. Por tal motivo, Dworkin afirma: "Si el Gobierno no se toma los derechos en serio, entonces tampoco se está tomando con seriedad el derecho". ${ }^{31}$

Los derechos fundamentales también desempeñan una importante función en la actividad judicial, ya que no sólo presentan una dimensión subjetiva de protección del individuo, sino que constituyen también criterios preferentes para la interpretación jurídica. Ante un caso difícil, el juez debe buscar no cualquier solución, sino indagar los alcances que los derechos fundamentales tienen en el caso concreto. En otros términos, debe optar por aquella solución que resulte más acorde con las exigencias de los derechos. El criterio hermenéutico a favor de las libertades - favor libertatis - tal vez sea el ejemplo más claro acorde con el planteamiento de Dworkin.

En suma, creo que la obra de Dworkin, es recomendable para todos los juristas preocupados por su labor, y preocupados porque los derechos sean tomados en serio, como lo señala nuestro autor.

\footnotetext{
28 Ibidem, p. 261.

29 Ibidem, p. 267.

30 Ibidem, p. 302.

31 Ibidem, p. 303.
} 


\section{La influencia de Dworkin en la jurisprudencia del Tribunal Electoral del Poder Judicial de la Federación}

En este apartado, a través del análisis de algunas sentencias y jurisprudencia del Tribunal Electoral del Poder Judicial de la Federación, demostraré la influencia de nuestro autor, ya que considero que en los casos en análisis, el Tribunal Electoral adopta un método similar al de Hércules, buscando la mejor interpretación posible en la solución de los asuntos sometidos a su consideración.

En cuanto al reconocimiento de los principios, que en definición de nuestro autor, son estándares que han de observarse en virtud de una exigencia de justicia, equidad, o de alguna otra dimensión de la moralidad; ${ }^{32}$ el Tribunal Electoral del Poder Judicial de la Federación, en el año 2000, en el estado de Tabasco, anuló por primera vez una elección, por una causa de nulidad no expresamente prevista en la norma, tomando en consideración la violación a principios constitucionales y legales, fundamentales para que cualquier tipo de elección sea considerada válida. ${ }^{33}$

De haber seguido la letra de la ley, es decir, de haber considerado al derecho como un conjunto de normas (reglas), el Tribunal Electoral no hubiese anulado la elección de gobernador de esa entidad federativa.

Lo anterior significa que el Tribunal Electoral del Poder Judicial de la Federación, al igual que Dworkin, estimó que el sistema jurídico mexicano, además de estar conformado por reglas - primarias y secundarias de acuerdo con Hart-, también se encuentra conformado por principios.

La citada decisión, dio pauta al establecimiento de la tesis X/2001, de rubro: Elecciones. PRINCIPIOS CONSTITUCIONALES Y LEGALES QUE SE DEBEN OBSERVAR PARA QUE CUALQUIER TIPO DE ELECCIÓN SEA CONSIDERADA VÁLIDA. ${ }^{34}$

32 Dworkin, Ronald, Los derechos en serio, cit., p. 72.

33 Véase sentencia dictada en el expediente SUP-JRC-487/2000 y acumulado, en $h t t p$ : //200.23.107.66/siscon/gateway.dll/nSentencias/nSuperior/n2000/jrc/sup-jrc-0487-2000.h tm? fn=document-frame.htm $\$$ f=templates $\$ 3.0$.

${ }_{34}$ Disponible en $h t t p: / / 200.23 .107 .66 /$ siscon/gateway.dll/nJurisprudenciayTesis/nVigen tesTercerayCuartaEpoca/ntesisvigentes/n2001/T-X-2001.htm. 
La tesis señalada, precisa que los principios constitucionales y legales que se deben observar para que cualquier tipo de elección sea considerada válida, son, entre otros: elecciones libres, auténticas y periódicas; el sufragio universal, libre, secreto y directo; que en el financiamiento de los partidos políticos y sus campañas electorales prevalezca el principio de equidad; la organización de las elecciones a través de un organismo público y autónomo; la certeza, legalidad, independencia, imparcialidad y objetividad como principios rectores del proceso electoral, el establecimiento de condiciones de equidad para el acceso de los partidos políticos a los medios de comunicación social, el control de la constitucionalidad y legalidad de los actos y resoluciones electorales.

Como puede observarse, el Tribunal Electoral del Poder Judicial de la Federación, en la tesis de referencia, determinó cuáles son los estándares que deben de observarse, para que cualquier tipo de elección sea considerada válida. Además, los mencionados principios fueron establecidos atendiendo a criterios de justicia y equidad, dado que su no observancia, se traduce en contiendas electorales desaseadas, donde existe compra y coacción del voto, y todo tipo de prácticas que atentan contra la libertad del sufragio.

Es por ello que la sentencia de nulidad por violación a principios constitucionales, dio origen al establecimiento de la conocida como causal abstracta de nulidad de elección, cuya denominación corresponde a una causal no expresamente prevista en una norma, que se actualiza cuando se violan de forma grave y generalizada, los principios constitucionales y legales que deben observarse para que una elección sea considerada válida. ${ }^{35}$

Cabe destacar que en el momento en que fue emitida la mencionada resolución, inmediatamente se generaron reacciones adversas, sobre todo, de juristas formados bajo la corriente Kelseniana, los que señalaron que resultaba inadmisible que el Tribunal Electoral haya tomado la decisión de anular una elección, por una causal no expresamente prevista por la norma.

De tal suerte que, en la reforma constitucional en materia electoral publicada en el Diario Oficial de la Federación, el 13 de noviembre de

35 Véase tesis: Nulidad de elección. Causa abstracta (Legislación De TABasco y SIMILARES), en http://www.ordenjuridico.gob.mx/Publicaciones/CDs2006/CDElectoral/ $p d f / J 175 . p d f$. 
2007, se aprobó una modificación al artículo 99, en la que se dispuso que las salas Superior y regionales del Tribunal Electoral, sólo pueden declarar la nulidad de una elección por las causales que expresamente se establezcan en las leyes.

Con lo anterior, se buscó limitar el activismo judicial del Tribunal Electoral, para que sólo por las causas expresamente previstas por las leyes, se pudiese anular una elección.

Empero, posterior a la reforma constitucional en materia electoral de 2007, la Sala Superior ha mantenido su criterio de nulidad de elección por violación a los principios constitucionales, como en el caso "Yurécuaro" (SUP-JRC-604/2007), ${ }^{36}$ o el caso "Acapulco" (SUP-JRC165/2008), ${ }^{37}$ por lo que, la causal abstracta de nulidad de elecciones, muerta con la reforma electoral citada, ha evolucionado hacia la causal por violación a principios constitucionales.

Los argumentos de la Sala Superior que sustentan este cambio se pueden sintetizar de la siguiente manera:

- La reforma constitucional de 2007 dotó de competencia a las salas del Tribunal Electoral para inaplicar una norma contraria a la Constitución, convirtiéndolas en auténticos tribunales de constitucionalidad.

- La referencia expresa a que sólo puede declararse la nulidad de elecciones por aquellas causas previstas en ley, se debe interpretar de forma sistemática con el resto del ordenamiento, pues dicha restricción derivada de una interpretación letrista, haría nugatorio el sentido de la reforma de convertir a las salas del Tribunal Electoral en auténticos tribunales de constitucionalidad, como se mencionó en líneas anteriores. En otras palabras: anular elecciones sólo por las causales reconocidas en la ley convertiría a las salas del Tribunal Electoral en tribunales de legalidad, circunstancia incompatible con la reforma.

Igualmente, cabe señalar que en las sentencias antes señaladas se estableció, la metodología para el análisis de una causal de nulidad de

${ }^{36}$ http://portal.te.gob.mx/colecciones/sentencias/html/SUP/2007/JRC/SUP-JRC-006042007.htm.

${ }^{37}$ http://portal.te.gob.mx/colecciones/sentencias/html/SUP/2008/JRC/SUP-JRC-001652008.htm. 
elección por violación a los principios constitucionales, la que obliga al operador jurídico a seguir los siguientes pasos:

- Acreditar que, sin lugar a dudas, existió una violación a un principio constitucional.

- De igual modo, corroborar que dicha irregularidad es grave, lo que debe operarse en la medida en que involucra la conculcación de determinados principios o la vulneración de ciertos valores fundamentales constitucionalmente previstos y que son indispensables para estimar que se está en presencia de una elección democrática.

- Finalmente, demostrar que la violación reclamada fue determinante para el sentido de la elección, de acuerdo con la jurisprudencia de la Sala Superior, a los criterios cuantitativo y cualitativo, esto es, a la magnitud medible o calculable racionalmente.

En criterios más recientes, el Tribunal Electoral, bajo supuestos dworkinianos, afortunadamente continuó en una línea progresiva, de tal suerte que hoy día, los principios siguen teniendo pleno reconocimiento por ese órgano jurisdiccional, añadiendo además, los derivados de los tratados internacionales en materia de derechos humanos suscritos por el Estado mexicano.

En ese sentido, la Sala Superior, consideró en el dictamen relativo al Cómputo Final, Calificación de la Elección, Declaración de Validez y de Presidente Electo de los Estados Unidos Mexicanos, ${ }^{38}$ que puede declarar la invalidez de la elección, por violación a los principios constitucionales, cuando se presenten los siguientes elementos:

a) La existencia de hechos que se consideren violatorios de algún principio constitucional, o parámetro de derecho internacional aplicable (violaciones graves, sustanciales).

b) Que las referidas violaciones se encuentren plenamente acreditadas.

c) Que se constate el grado de afectación que la violación haya producido dentro del proceso electoral.

d) Que las violaciones sean cuantitativa o cualitativamente determinantes para el resultado de la elección.

38 http://portal.te.gob.mx/proceso2012. 
Por tanto, la Sala Superior del Tribunal Electoral refirió que la calificación jurisdiccional de validez de la elección, debe efectuarse conforme al parámetro de constitucionalidad y convencionalidad, y en consecuencia, conforme a los principios y valores que inspiran el sistema jurídico mexicano.

Conforme a lo anterior, es oportuno destacar algunos principios y valores constitucionales y convencionales en materia electoral, de acuerdo a los cuales se debe calificar la validez de la elección, a saber:

- Los derechos humanos de votar, ser votado, asociación y afiliación, en cuanto a principios; previstos en los artículos 35, fracciones I, II y III, y 41, párrafo 2, fracción I, párrafo 2, de la Constitución general de la República; 23.1 inciso b, de la Convención Americana sobre Derechos Humanos, y 25, inciso b, del Pacto Internacional de Derechos Civiles y Políticos.

- El derecho de los ciudadanos a tener acceso, en condiciones generales de igualdad, a las funciones públicas del país, previsto en los artículos 23.1, inciso $c$, de la Convención Americana sobre Derechos Humanos, y 25, inciso $b$, del Pacto Internacional de Derechos Civiles y Políticos.

- El principio de elecciones libres, auténticas y periódicas, previsto en los artículos 41, párrafo 2, de la Constitución general de la República; 23.1, inciso $b$, de la Convención Americana sobre Derechos Humanos, y 25, inciso $b$, del Pacto Internacional de Derechos Civiles y Políticos.

- El principio del sufragio universal, libre, secreto y directo, establecido en los artículos 41, párrafo 2, base I, párrafo 2, y 116, fracción IV, inciso $a$, de la Constitución general de la República; 23.1 inciso $b$, de la Convención Americana sobre Derechos Humanos, y 25, inciso $b$, del Pacto Internacional de Derechos Civiles y Políticos.

- El principio de libertad de expresión y del derecho a la información -y su maximización en el debate político que precede a las elecciones-, consignado en los artículos 6o. y 7o. de la Constitución general de la República; 25.1 de la Convención Americana sobre Derechos Humanos, y 19 del Pacto Internacional de Derechos Civiles y Políticos.

- El principio conforme al cual, los partidos políticos nacionales deben contar de manera equitativa con elementos para llevar a 
cabo sus actividades, de acuerdo a lo previsto por el artículo 41, párrafo 2, base II, de la Constitución general de la República.

- El principio de equidad en el financiamiento público, prescrito por los artículos 41, párrafo 2, base II, y 116, fracción IV, inciso $g$, de la Constitución general de la República.

- El principio de prevalencia de los recursos públicos sobre los de origen privado, establecido por el artículo 41, párrafo 2, base II de la Constitución.

- El principio de acuerdo al cual la organización de las elecciones se debe llevar a cabo por un organismo público, dotado de autonomía e independencia, dispuesto por el artículo 41, párrafo 2, base V, de la Constitución General de la República.

- Los principios rectores de la función electoral: certeza, legalidad, independencia, imparcialidad y objetividad, establecidos por los artículos 41, párrafo 2, base V, y 116, fracción IV, inciso b, de la Constitución general de la República.

- Los principios de constitucionalidad y legalidad de los actos y resoluciones de las autoridades electorales, previstos por el artículo 41, párrafo 2, base VI de la Constitución general de la República.

- El derecho a la tutela judicial efectiva, establecido por los artículos 17; 41, párrafo 2 , base VI, y 116 , fracción IV, inciso $l$, de la Constitución general de la República, y 25.1 de la Convención Americana sobre Derechos Humanos.

- El principio de definitividad en materia electoral, dispuesto en los artículos 41, párrafo 2, base VI, y 116, fracción IV, inciso $m$, de la Constitución general de la República.

- El principio de equidad en la contienda electoral entre los partidos políticos y sus candidatos, previsto en el artículo 134, en relación con el 41, párrafo 2, base II, de la Constitución federal.

- El principio de acuerdo con el cual, sólo la ley puede establecer las causales de nulidad, prescrito en el artículo 99, párrafo 4, fracción II, párrafo 2 , de la carta magna.

Los referidos principios se encuentran presentes en el ordenamiento jurídico mexicano, y constituyen premisas esenciales o elementos para considerar una elección como democrática, cuyo cumplimiento también es fundamental para considerar constitucionalmente valida una elección. 
Siguiendo a Dworkin, los principios de cuenta, pueden ser calificados como principios, no por su origen, ni por su fuente -Constitución-, sino por su peso argumentativo, es decir, por su peso específico, por su contenido, de acuerdo con un complicado procedimiento de búsqueda de la más sólida teoría del derecho.

El establecimiento de dichos estándares democráticos para considerar que una elección es válida, constituye un esfuerzo argumentativo sin precedentes por parte del Tribunal Electoral, en el que sin duda, parte del ideal regulativo de presentar la teoría del derecho más lógica y mejor fundada, que se pueda presentar como justificación de las normas institucionales y sustantivas explícitas.

En la actualidad, nadie podrá objetar que los referidos principios, son fundamentales para poder hablar de una elección democrática. Es por ello que, siguiendo a Dworkin, los principios mencionados encuentran su justificación en estándares de justicia y equidad, esto es, en una dimensión jurídica y moral.

Se insiste en que si el Tribunal Electoral hubiese considerado como derecho, sólo las normas expresamente establecidas, no habría podido anular la elección de gobernador del estado de Tabasco, ni algunas otras elecciones, como en Torreón, Colima, Zamora, Yurécuaro, Huazalingo o Zimapán, entre otros casos.

Para destacar la importancia de la nulidad de elección por violación a los principios constitucionales, se citan los casos Zamora (SUPREC-034/ 2003) ${ }^{39}$ y Torreón (SUP-REC-009/2003 y acumulado), ${ }^{40}$ en donde los agravios hechos valer por los actores, fueron la manipulación de programas sociales, el uso de recursos públicos a favor de los candidatos del Partido Acción Nacional, la distribución de propaganda negra (Torreón) y de propaganda religiosa (Zamora), la presencia del grupo de choque "hombres de negro" y la inequidad en el acceso a los medios de comunicación. Agravios que fueron probados a través de declaraciones, notas periodísticas, pruebas técnicas como videos, documentales privados, etcétera, los cuales adminiculados de manera armónica condujeron a la nulidad de la elección en cada caso. En esos asuntos, no existía una norma que expresamente sancionara con la nulidad de la elección, la comisión de dichas conductas.

39 http://portal.te.gob.mx/colecciones/sentencias/html/SUP/2003/REC/SUP-REC-0003 4-2003.htm.

${ }^{40}$ http://portal.te.gob.mx/colecciones/sentencias/html/SUP/2003/REC/SUP-REC-0000 9-2003.htm. 
En ese orden de ideas, imaginemos por un momento un juez que sólo reconoce como derecho valido, el que está expresamente reconocido en una norma. Siendo congruente con sus creencias, ante los anteriores casos, hubiese adoptado la decisión de no anular dichos comicios, por no contar con una norma que expresamente previera dicho supuesto; con el consiguiente resultado de mantener validas unas elecciones completamente desaseadas, en donde no se puede decir que el resultado fue producto de libre expresión de los ciudadanos.

En cambio, un juez como Hércules, que reconoce como derecho además de las reglas, a un conjunto de principios que encuentran su justificación en estándares de justicia, equidad o cualquier otra dimensión de moralidad; adopta la mejor determinación que sea resultado de la ponderación del sistema jurídico en su conjunto - principios y reglas-, de acuerdo al ideal democrático de unas elecciones libres, auténticas y periódicas. De tal suerte que bajo esas creencias, un juez o tribunal al estilo dworkiniano - como el Tribunal Electoral-, haya tomado la determinación de anular esas elecciones, a pesar de no contar con una norma que expresamente lo facultara para hacerlo.

Es en esta parte, donde siguiendo a Dworkin, se aprecia el activismo judicial que ha tenido el Tribunal Electoral, con la finalidad de restablecer los principios del Estado constitucional y democrático de derecho, sancionando, de la manera más grave, aquellos comicios que no se ajusten a esos estándares fijados para que las elecciones sean consideradas como un fiel reflejo de la voluntad popular.

En cuanto a la protección de los derechos, existe una vasta jurisprudencia del Tribunal Electoral, donde lo fundamental es tomar los derechos en serio, como lo señala nuestro autor.

Como se verá, para el Tribunal Electoral, los derechos fundamentales también desempeñan una importante función en su actividad judicial, ya que no sólo presentan una dimensión subjetiva de protección del individuo, sino que constituyen también criterios preferentes para la interpretación jurídica.

Por lo que ante un caso difícil, el juez debe buscar no cualquier solución, sino indagar los alcances que los derechos fundamentales tienen en el caso concreto. En otros términos, debe optar por aquella solución que resulte más acorde con las exigencias de los derechos.

El criterio hermenéutico a favor de las libertades - favor libertatis - tal vez sea el ejemplo más claro acorde con el planteamiento de Dworkin. 
Esta revista forma parte del acervo de la Biblioteca Jurídica Virtual del Instituto de Investigaciones Jurídicas de la UNAM

Acorde a lo expuesto por nuestro autor, el Tribunal Electoral, en la jurisprudencia 29/2002, de rubro: Derechos fundamentales DE CARÁCTER POLÍTICO-ELECTORAL. SU INTERPRETACIÓN Y CORRELATIVA APLICACIÓN NO DEBE SER RESTRICTIVA, ${ }^{41}$ ha sustentado que interpretar en forma restrictiva los derechos subjetivos públicos fundamentales de asociación en materia política y de afiliación política electoral consagrados constitucionalmente, implicaría desconocer los valores tutelados por las normas constitucionales que los consagran. Por ello, cabe hacer una interpretación con un criterio extensivo, toda vez que no se trata de una excepción o de un privilegio, sino de derechos fundamentales consagrados constitucionalmente, los cuales deben ser ampliados, no restringidos ni mucho menos suprimidos.

Lo anterior, precisa el Tribunal, en virtud de que las pautas interpretativas que rigen la determinación del sentido y alcances jurídicos de una norma no permiten que se restrinja o haga nugatorio el ejercicio de un derecho fundamental, como lo son los de asociación política y de afiliación político-electoral; por el contrario, toda interpretación y la correlativa aplicación de una norma jurídica deben ampliar sus alcances jurídicos para potenciar su ejercicio, siempre que aquélla esté relacionada con un derecho fundamental. Sin que esto signifique en forma alguna sostener que los derechos fundamentales de carácter político sean derechos absolutos o ilimitados.

En congruencia con el anterior criterio, la Sala Superior del Tribunal Electoral, al resolver los expedientes SUP-JDC-0695/2007, ${ }^{42}$ determinó que el derecho de ser votado no debe vulnerarse por ocupar un cargo de elección popular. Destacadamente, la Sala Superior, precisó que el hecho de que un ciudadano esté en ejercicio de un cargo de elección popular, no impide que pueda registrarse como candidato para contender por otro cargo de esa naturaleza, aun cuando no hubiera concluido el periodo para el que fue electo, siempre que se separe dentro del término legalmente exigido.

En el caso concreto, la Sala Superior inaplicó la prohibición prevista en el artículo 42, párrafo 3, de la Constitución de Baja California, consistente en que un presidente municipal de un ayuntamiento no puede

${ }^{41}$ http://www.te.gob.mx/iuse/tesisjur.aspx?idtesis=564ঊtpoBusqueda=S↔sWord=Dere chos,Pol\%C3\%ADtico-Electorales.

42 http://portal.te.gob.mx/colecciones/sentencias/html/SUP/2007/JDC/SUP-JDC-00695 $-2007 . h t m$. 
ser electo gobernador del estado, durante el periodo para el cual fue electo, aun cuando se separe de su cargo; bajo el argumento de que contraviene los tratados internacionales y, en especial, a los artículos 1o., 2o., 29 y 30, de la Convención Americana sobre Derechos Humanos, los cuales forman parte del sistema jurídico mexicano.

La disposición en comento, es del tenor siguiente:

Artículo 42. No podrán ser electos Gobernador del Estado: el Secretario General de Gobierno, los Magistrados y Jueces del Tribunal Superior de Justicia del Estado, el Procurador General de Justicia y los Secretarios y Directores del Poder Ejecutivo, salvo que se separen de sus cargos en forma definitiva, noventa días antes de la elección.

Los Militares en servicio activo y los titulares de los cuerpos policíacos, no podrán ser electos Gobernador del Estado, salvo que se separen de sus cargos en forma provisional, noventa días antes de la elección.

Los Diputados y Senadores del Congreso de la Unión, Diputados locales, Presidentes Municipales, Síndicos Procuradores y Regidores de los Ayuntamientos durante el periodo para el que fueron electos; aún cuando se separen de sus cargos; con excepción de los suplentes siempre y cuando éstos no estuvieren ejerciendo el cargo.

Con ese respecto, la Sala Superior sostuvo que cualquier condición adicional que se imponga al ejercicio de los derechos político-electorales, deberá basarse exclusivamente en calidades inherentes a la persona, además de ser necesaria e idónea para lograr la finalidad perseguida, y obedecer a criterios objetivos, racionales y proporcionales, que tengan como base algún principio o valor fundamental del sistema constitucional. Por tanto, la limitación a la posibilidad de contender de un ciudadano, durante el desempeño de un cargo de elección popular, debe hacerse en armonía con el texto fundamental y los instrumentos internacionales en cuanto potencian el derecho a ser votado.

En armonía con Dworkin, la Sala Superior realizó una interpretación a favor de los derechos, a la luz de los tratados internacionales suscritos por el presidente de la República y ratificados por el Senado, en relación con el contenido y alcance del derecho fundamental de ser votado y, en especial, con lo dispuesto en los artículos 1o., 2o., 29 y 30 de la Convención Americana sobre Derechos Humanos; de donde se obtiene que la limitación prevista en el citado artículo de la Constitución de Baja California, no encuadra en los supuestos permitidos para 
Esta revista forma parte del acervo de la Biblioteca Jurídica Virtual del Instituto de Investigaciones Jurídicas de la UNAM

restringir ese derecho fundamental. Por lo cual, en el caso, se privilegió la interpretación normativa tendente a maximizar el ejercicio del derecho a ser votado.

En efecto, en el caso, la Sala Superior potenció el derecho fundamental a ser votado, al considerar que la referida limitante de la Constitución de Baja California, restringe el ejercicio del mencionado derecho, porque se trata de una restricción que no corresponde ni a calidades intrínsecas de la persona, ni resulta necesaria, proporcional e idónea para tutelar alguno de los principios rectores de cualquier elección.

Se sustentó lo anterior, porque, en términos del artículo 79 de la Constitución local y 32 de la Ley de Instituciones y Procesos Electorales del Estado de Baja California, el cargo de presidente municipal, se adquiere por reunir los requisitos previstos en dicha legislación, y por resultar electo en el proceso electoral atinente. Por tanto, ocupar el cargo de presidente municipal, no es una calidad inherente a la persona.

También se consideró que no es una medida necesaria, idónea y proporcional, de conformidad con los criterios para determinar la validez de las restricciones a derechos fundamentales, asumidos por la Corte Interamericana de Derechos Humanos, en el caso Yatama vs. Nicaragua, en la sentencia del 23 de junio de 2005.

Al respecto, la Sala Superior estimó que la prohibición contenida en la Constitución de Baja California, no era idónea para alcanzar la finalidad perseguida, consistente en lograr el adecuado y responsable desempeño de un cargo de elección popular, pues éste está asegurado a través de diversos mecanismos constitucionales, entre los cuales pueden ubicarse los preventivos - revisión, análisis, y auditorías de las cuentas públicas; la planeación democrática del desarrollo estatal y municipal; la aprobación o la reprobación de los convenios sobre cuestión de límites territoriales con las entidades de la Federación, etcétera-; los correctivos - que tiene que ver con la solución de conflictos a cargo de las instancias competentes para resolverlos-, y los sancionatorios o punitivos - la suspensión o desaparición de ayuntamientos, o bien, la suspensión o la revocación de los ayuntamientos; la declaración de procedencia contra los servidores públicos, y el juicio político-.

Igualmente, consideró que del hecho de que un servidor público de elección popular cumpla de manera íntegra con el periodo para el cual fue electo, no necesariamente implica que observará su progra- 
ma de gobierno municipal o legislativo, por ejemplo, ya que entre los mecanismos adecuados para asegurar, mediante la amenaza de una sanción que se cumpliría con las oferta política durante las campañas, por ejemplo, sería a través de los procedimientos de revocación de mandato o el llamado mandato imperativo, los cuales no están previstos en la legislación del estado de Baja California.

En consecuencia, se sostuvo que no era preciso que con disposiciones como las semejantes se inhiban conductas no deseadas.

Por el contrario, la Sala Superior razonó que la posibilidad de que un sujeto que ocupa un cargo de elección popular pueda continuar con su carrera política, mediante la posibilidad de que para ello fuera suficiente su separación oportuna definitiva o provisional, operaría como un incentivo positivo, ya que su éxito ante el electorado estaría asegurado por su gestión pública como legislador o munícipe, y no porque se limite su derecho de seguir ocupando un cargo público de manera inmediata a aquel de que se hubiere separado.

Adicionalmente, la Sala Superior argumentó que con la referida interpretación a favor del derecho de ser votado, no se quebrantaba la soberanía popular ni se impide la integración de los órganos de gobierno, mucho menos se imposibilita el correcto funcionamiento de las instituciones y la continuidad de las tareas legislativas y de gobierno, mediante la separación del cargo de manera oportuna por quien aspire a otro puesto de elección popular, ya que existen instrumentos para suplir las ausencias.

Por todo lo antes expuesto, la Sala Superior del Tribunal Electoral, concluyó que la norma limitativa del derecho a ser votado, prevista en el artículo 42, párrafo 3, de la Constitución de Baja California, produciría la disminución de la participación ciudadana, el pluralismo político y la profesionalización de la carrera política en detrimento de la consolidación de un sistema democrático.

El criterio apuntado, dio origen a la Jurisprudencia 02/2010, de rubro: Derecho a SER Votado. No DEBE VULNERARSE POR OCUPAR UN CARgo de EleCCión Popular (LEgislación de BAJa CAlifornia). ${ }^{43}$

Es en este tipo de casos, donde la labor del Tribunal Electoral se asemeja al juez Hércules dworkiniano, dado que asegura al máximo la

${ }^{43}$ http://www.te.gob.mx/iuse/tesisjur.aspx?idtesis $=1351$ \&tpoBusqueda $=$ Ser $s$ Word $=D E$ RECHO,A,SER, VOTADO.,NO,DEBE, VULNERARSE,POR,OCUPAR, UN,CARGO,DE,EL ECCI\%C3\%93N,POPULAR,(LEGISLACI\%C3\%93N,DE,BAJA,CALIFORNIA. 
vigencia y plena efectividad de los derechos fundamentales, incluso, en contra de la decisión de las mayorías plasmada en una norma.

Se aprecia cómo el Tribunal Electoral se toma los derechos en serio, al dejar de aplicar una disposición normativa que no cumple con los estándares necesarios que justifiquen la limitación al derecho fundamental de ser votado.

Precisamente en eso consiste tomarse los derechos en serio. Recordemos que Dworkin señala que, un gobierno para quien los derechos no sean un simple recurso retórico, un gobierno que reconozca los derechos: "Debe prescindir de la aseveración de que los ciudadanos jamás tienen derecho a infringir sus leyes, y no debe definir los derechos de los ciudadanos de tal modo que queden aislados por supuestas razones del bien general". ${ }^{4}$

De lo anterior se advierte por qué Dworkin señala la desobediencia de la ley, como rasgo distintivo de un derecho fundamental que lo sea auténticamente.

Cabe señalar, que se valora aún más la labor del Tribunal Electoral en el caso bajo estudio, porque en la fecha en la que se resolvió - 6 de julio de 2007-, contaba con una limitación de índole jurisprudencial, impuesta por la Suprema Corte de Justicia de la Nación - a través de la Jurisprudencia 2/2000-, para dejar de aplicar una norma que fuese contraria a la Constitución Política de los Estados Unidos Mexicanos.

Sin embargo, lo anterior no fue obstáculo para que el Tribunal Electoral, haciendo una interpretación conforme a los tratados internacionales en materia de derechos humanos, realizará un ejercicio de control de convencionalidad, dejando de aplicar la norma de la Constitución de Baja California, por limitar el derecho fundamental a ser votado.

Actualmente, a partir de la reforma constitucional publicada en el Diario Oficial de la Federación en noviembre de 2007, las salas del Tribunal Electoral del Poder Judicial de la Federación, cuentan con competencia expresa para dejar de aplicar una norma cuando se considere contraria a la carta magna. Y a partir de la reforma constitucional en materia de derechos humanos de junio de 2011, se ha inaugurado un nuevo paradigma en la interpretación y protección de los derechos humanos, dado que todas las autoridades, en el ámbito de sus respectivas competencias, tienen la obligación de promover, respetar y ga-

${ }_{44}$ Dworkin, Ronald, Los derechos en serio, cit., p. 302. 
Esta revista forma parte del acervo de la Biblioteca Jurídica Virtual del Instituto de Investigaciones Jurídicas de la UNAM

rantizar los derechos humanos consagrados tanto en la Constitución como en los tratados internacionales en la materia suscritos por el Estado mexicano.

Como se expresó, es vasta la jurisprudencia del Tribunal Electoral donde nos deja en claro que los derechos fundamentales no son objeto de negociación, en donde nos precisa que los derechos deben respetarse aún en contra de la voluntad de las mayorías.

Sería una labor titánica, en este modesto ensayo, dar cuenta de la totalidad de los casos y criterios asumidos por el Tribunal Electoral a favor de los derechos fundamentales. ${ }^{45}$

Empero, ello no es impedimento para concluir, siguiendo a Dworkin, que el Tribunal Electoral, al tomarse los derechos en serio, también se toma con seriedad el derecho.

\section{Fuentes consultadas}

Alexy, Robert, "Sistema jurídico, principios jurídicos y razón práctica”, Doxa, 5, 1988.

CÁceres Nieto, Enrique, Constructivismo jurídico y meta teoría del derecho, México, UNAM, 2007.

Dworkin, Ronald, Los derechos en serio, Barcelona, Ariel, 1999.

-_-, El imperio de la justicia, Barcelona, Gedisa, 1998.

-_- Law's Empire, Londres, Fontana Press, 1986.

Hart, H. L. A, El concepto de Derecho, 2a. ed., trad. de Genaro Carrió, México, UNAM.

- ——, "El nuevo desafío al positivismo jurídico", trad. de F. Laporta, L. Hierro y J. R. Páramo, Sistema, núm. 36, mayo de 1980.

45 Entre otros criterios donde el Tribunal Electoral maximiza los Derechos Fundamentales, de manera enunciativa, mas no limitativa, podemos referir los siguientes: $a$ ) tesis relevante XV/2007, de rubro: SUSPENSIÓN DE LOS DERECHOS POLÍTICO-ELECTORALES DEL CIUDADANO PREVISTA EN LA FRACCIÓN II DEL ARTÍ́CULO 38 CONSTITUCIONAL. SólO PROCEDE CUANDO SE PRIVE DE LA LIBERTAD; $b$ ) tesis relevante XXX/2007, cuyo rubro es: Suspensión de derechos político-electorales. Concluye cuando Se sustiTUYE LA PENA PRIVATIVA DE LIBERTAD QUE LA PRODUJO (LEGISLACIÓN DEL ESTADO DE MÉXICO Y SIMILARES), y c) jurisprudencia 20/2010, cuyo rubro es: DeRECHO POLÍtico ELECTORAL A SER VOTADO. INCLUYE EL DERECHO A OCUPAR Y DESEMPEÑAR EL CARGO. 
Esta revista forma parte del acervo de la Biblioteca Jurídica Virtual del Instituto de Investigaciones Jurídicas de la UNAM

Electrónicas

http://200.23.107.66/siscon/gateway.dll/nSentencias/nSupe rior/n2000/jrc/sup-jrc-0487-2000.htm?fn=document-frame. htm $\$ f=$ templates $\$ 3.0$.

http://200.23.107.66/siscon/gateway.dll/nJurisprudenciayTesis/nVigen tesTercerayCuartaEpoca/ntesisvigentes/n2001/T-X-2001.htm.

http://www.ordenjuridico.gob.mx/Publicaciones/CDs2006/CDElecto $\mathrm{ral} / \mathrm{pdf} / J 175 . p d f$.

http://portal.te.gob.mx/colecciones/sentencias/html/SUP/2007/JRC/ SUP-JRC-00604-2007.htm.

http://portal.te.gob.mx/colecciones/sentencias/html/SUP/2008/JRC/

SUP-JRC-00165-2008.htm.

http://portal.te.gob.mx/colecciones/sentencias/html/SUP/2003/REC/ SUP-REC-00034-2003.htm.

http://portal.te.gob.mx/colecciones/sentencias/html/SUP/2003/REC/

SUP-REC-00009-2003.htm.

http://www.te.gob.mx/iuse/tesisjur.aspx?idtesis=564\&tpoBusqueda= S\&sWord=Derechos,Pol\%C3\%ADtico-Electorales.

http://portal.te.gob.mx/colecciones/sentencias/html/SUP/2007/JDC/ SUP-JDC-00695-2007.htm.

http://www.te.gob.mx/iuse/tesisjur.aspx?idtesis=1351\&tpoBusqueda $=$ S\&sWord=DERECHO,A,SER,VOTADO.,NO,DEBE,VULNERAR SE,POR,OCUPAR,UN,CARGO,DE,ELECCI\%C3\%93N,POPULA R,(LEGISLACI\%C3\%93N,DE,BAJA,CALIFORN. 